\title{
Moisture-Catalyzed Slow Release of Sex Pheromone from Microcrystals in Controlling Phyllophaga Pests
}

\author{
Pathik Sahoo ${ }^{1, *}$ and Pradip Das ${ }^{2, *}$
}

\begin{abstract}
Pheromones form Primary Ammonium Monocarboxylate (PAM) synthons based supramolecular container of sex pheromone to control Phyllopaga pests in greenway. Therein charge-assisted $\mathrm{H}$-bonds are highly stable in aprotic solvents like diethyl ether, dichloromethane, or chloroform, but protic solvent like water disintegrates it even in the moisture state. By preparing the micro-thin needle-shaped supramolecular container, we released sex pheromone under an open atmosphere. Herein, the labile proton in PAM salt drifts from amino acid methyl ester ammonium to carboxylate moiety under moisturized open environment before releasing the pheromone. This moisture-driven pheromone releasing device could be used to trap the pests physically. The nuclear magnetic resonance (NMR) spectroscopy showed the first-order kinetics while releasing the sex pheromone from the supramolecular container in moist air. The density functional theory (DFT) and experimental studies described here establish the green method of releasing the sex pheromone to trap the pests physically. This method could open a window towards pesticide-free green organic farming.
\end{abstract}

Keywords: Supramolecular container; Moisture-catalysed pheromone release; NMR monitoring; Phyllophaga pests.

Received: 1 July 2021; Accepted: 7 August 2021.

Article type: Communication.

\section{Introduction}

Slow-release of sex pheromone ${ }^{[1-3]}$ from supramolecular container $^{[4-7]}$ is a potential green pest control method, which holds out promise for the future. Pheromone can be released by different devices like supramoleculargel,,${ }^{[1]}$ or from a small vial with a narrow slit at the cap. In case of supramolecular gel, the gel must be a hydrogel and the releasing can not be controlled, once it is doped in gel. On the other hand, the release from a vial would be extremely fast as pheromones are volatile. To control the release, we need to develop a supramolecular device of sex-pheromone. However, in nature, insect releases pheromones intermittently at faster rates than the biosynthesis rate. ${ }^{[7]}$ Pheromones with primary amine functionality can be reacted with some monocarboxylic acids to form a Primary Ammonium Monocarboxylate (PAM) synthon $^{[4]}$ (Fig. 1a). It may be used as a supramolecular

1 Nano-Materials Field, Functional Chromophores Group, International Center for Materials Nanoarchitectonics, National Institute for Materials Science, Tsukuba, Japan.

${ }^{2}$ Department of Chemistry, Bose Institute, 93/1 Acharya Prafulla Chandra Road, Kolkata - 700009, West Bengal, India.

*Email: 2c.pathik@gmail.com (P. Sahoo),

pradipdas930@gmail.com (P. Das) container for a series of major sex pheromones, ${ }^{[8,9]}$ of several Phyllophaga species (various beetles). ${ }^{[10]}$ Some volatile methylated amino acid esters like valine- (pKa: 7.95), leucine(pKa: 7.95), isoleucine- (pKa: 7.98) methyl esters are the major sex pheromone of some major pests like Phyllophaga anxia, ${ }^{[1-14]}$ Phyllophaga lanceolate, ${ }^{[15]}$ Phyllophaga coleopteran, ${ }^{[16]}$ Phyllophaga georgiana, ${ }^{[13]}$ etc. These amino acid methyl esters were reacted with cinnamic acid (pKa: 4.44) and p-methyl cinnamic acid (pKa: 4.56) in dry diethyl ether to prepare the corresponding salts by combinatorial library approach. ${ }^{[4]}$ The names of some pests, their major sex hormones, host plant, and the affected region(s) are given in Table $1 .{ }^{[11-16]}$ In this study, we have arbitrarily chosen valinemethylester p-methylcinnamatesalt (Fig. 1a, $\Delta \mathrm{pK}_{\mathrm{a}}=$ $\mathrm{pK}_{\mathrm{a}}($ donor $)-\mathrm{pK}_{\mathrm{a}}$ (acceptor $\left.)=-3.39\right)$ to demonstrate the release of the major sex pheromone of P. anexia and $\mathrm{P}$. Georgiana to the environment. The borderline $\left|\Delta \mathrm{pK}_{\mathrm{a}}\right|$ is large enough to allow the efficient formation of the salt, yet small enough relative to $\left|\Delta \mathrm{pK}_{\mathrm{a}}\right|$ value for p-methyl cinnamic acidwater donor-acceptor system to allow controlled disintegration of the salt in the nominal presence of moist air. The $\Delta \mathrm{pK}_{\mathrm{a}}$ value $\left(\mathrm{H}_{2} \mathrm{O}: 15.74, \mathrm{H}_{3} \mathrm{O}^{+}:-1.74\right.$, p-methyl cinnamic acid: 4.78 , Valine methyl ester: 7.8 ) has a linear connection to the proton transfer energy $\left(E_{12}\right)$, the latter reflecting the energy difference before and after proton transfer for a particular 
Table 1. Some Phyllophaga pests are presented here with their common name, major sex pheromones, host plants and affected areas.

\begin{tabular}{|c|c|c|c|c|c|}
\hline No & Insects & Common Names & Sex Pheromones & Host Plants & Affected areas \\
\hline 11 & $\begin{array}{l}\text { Phyllopaga } \\
\text { anexia }\end{array}$ & Cranbery white grub & $\begin{array}{l}\text { L-valinemethylester, } \\
\text { L-isoleucinemethylester }\end{array}$ & $\begin{array}{l}\text { Cranberry, strawberry, roses, } \\
\text { forest trees, seedbeds }\end{array}$ & USA, Canada \\
\hline 22 & $\begin{array}{l}\text { Phyllopaga } \\
\text { lanceolata }\end{array}$ & Scarab beetle & L-leucinemethylester & $\begin{array}{l}\text { Spinach, lettuce, carrot, cowpea, } \\
\text { beans, irish potato, mustard, } \\
\text { onions, beans }\end{array}$ & $\begin{array}{l}\text { Iowa, Kanas, Texas, } \\
\text { Kansas, New Mexico, } \\
\text { Missouri, Nebraska, } \\
\text { Nevada,Colorado, }\end{array}$ \\
\hline 33 & $\begin{array}{l}\text { Phyllopaga } \\
\text { georgiana }\end{array}$ & Scarab beetle & L-valinemethylester & Roots of Cranberries & $\begin{array}{l}\text { East coast of USA, } \\
\text { Georgia }\end{array}$ \\
\hline
\end{tabular}
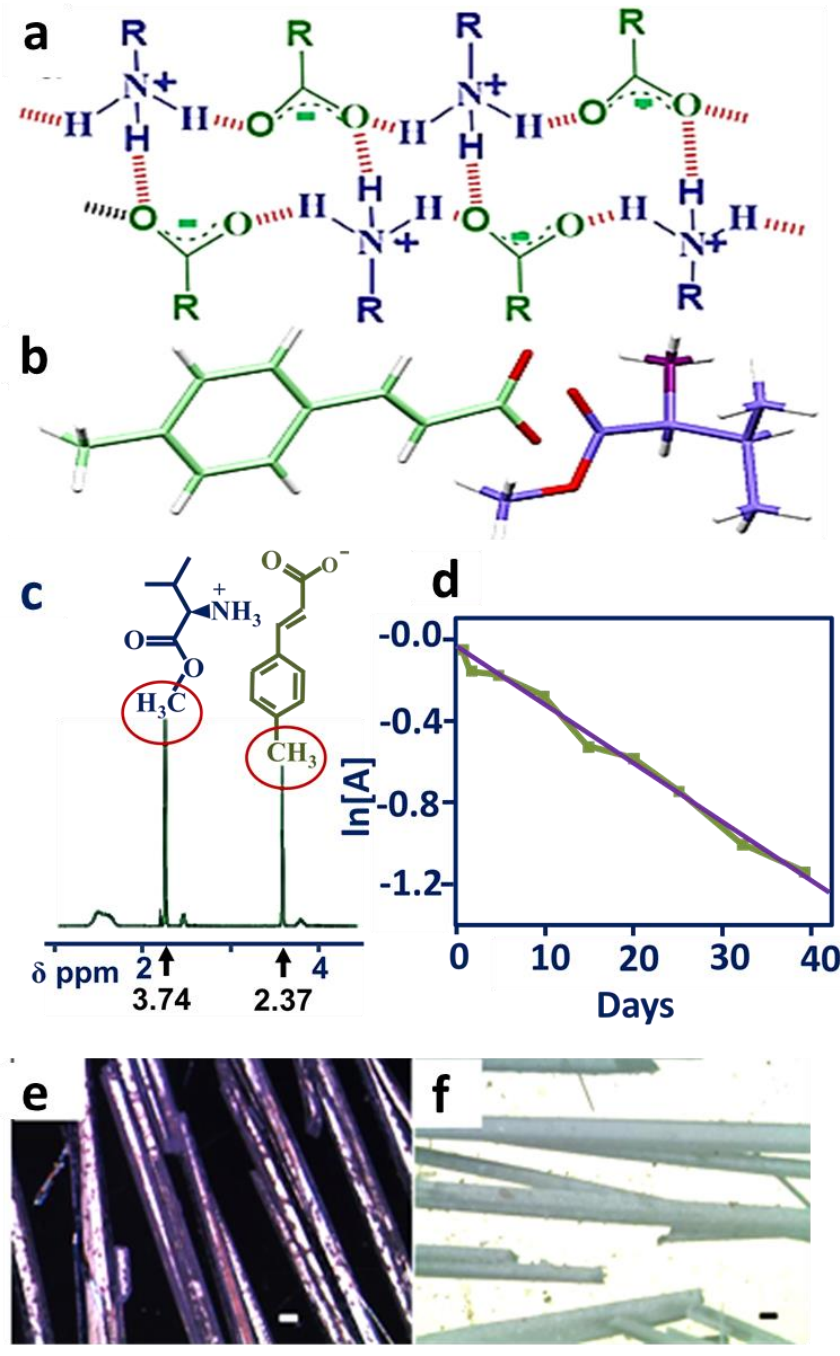

Fig. 1 (a) Structure of PAM Synthon. (b), Valinemethylester pmethyl cinnamate salt. (c), NMR signal of the salt. (d), first-order kinetics of pheromone release experiment. (e), before and (f), after pheromone release from salt under a polarized microscope (10 $\mu \mathrm{m}$ scale bar).

distance between the donor and acceptor atoms. ${ }^{[17]}$ The isolated ion-pair molecule is typical of higher energy - in a vacuum - than the uncharged reactant molecules for amino acid donor-acceptor systems. ${ }^{[17]}$ However, the molecular crystalline state of the salt, considered in the present example, show greater thermodynamic stability than the uncharged reactant molecules, owing to favorable dispersion and hydrogen-bonded interactions. ${ }^{[4]}$ Salt formation in these gelator molecules is possible in dry air, aprotic solvent. The salt decomposes instantly into the reactants in the presence of water and several other protic solvents. In polar aprotic solvents such as $\mathrm{CHCl}_{3}$ (dielectric constant $\sim 4.89$ ), ${ }^{[18]}$ the salt is soluble. However, the addition of anti-solvent substances, e.g. n-alkane, cyclohexane, to the solution leads to gel formation. ${ }^{[4]}$ The salt lattice does not exist in chloroform solution but charged molecular form, being stabilized by charge-transfer H-bonds. The latter are known to have greater bond energy than ordinary $\mathrm{H}$-bonds. One proton from carboxylic acid group get shifted towards the amine molecule and forms the positively and negatively charged groups, ammonium and carboxylate ions respectively. These group bonds together; a positively charged $\mathrm{N}\left(\mathrm{N}^{+}\right)$from an ammonium group forms bond with a negatively charged $\mathrm{O}_{\left(\mathrm{O}^{-}\right)}$ at carboxylate group via a proton. This is how a charge assisted $\mathrm{H}$ bond is formed between the ammonium and carboxylate moieties. In case of normal $\mathrm{H}$ bonding, two electronegative atoms forms a bond where proton is not shifter to other functional group completely, but share partially. Due to an incomplete proton shift, the two sharing atoms from two different functional groups just bear $\delta^{+}$and $\delta^{-}$charges only.

Water and other protic solvents can accept or donate protons. The charge-assisted $\mathrm{H}$-bonds between two solute molecular forms may break down, giving rise to uncharged valine methyl ester p-methyl cinnamic acid. When liquid water is used on the salt, the disintegration process is very fast and uncontrolled. The nominal presence of water in moist air makes this dissolution very much controlled and restricted to the surface layers of the salt crystallites, whatever their size and shape. As valine methyl ester volatilizes, new, smaller surface layers with fewer reactive sites get exposed to the moist air. Here water in the moist air functions as a catalyst to cause the decomposition of PAM synthon present as a solid. It is, therefore, an instance of heterogeneous catalysis. ${ }^{[19-23]}$ One important point to note that human sex hormones are not safe for nature and can be fatal for nature, ${ }^{[24]}$ but the insect sex 
pheromones are quite safe for the environment, as they never suppress fertility.

In this paper, the authors aim to use density functional theory (DFT) calculations to explore the conditions under which primary ammonium monocarboxylate (PAM) synthon formation is possible. Besides, an attempt is being made to furnish a proper theoretical interpretation of the order of the disintegration reaction of PAM synthon crystallites in the nominal presence of water or other protic solvents.

\section{Experimental}

\subsection{Materials and methods}

All the chemicals (Aldrich) and solvents (A.R. grade, Merc, India) are commercially available and were used as purchased. The FT-IR spectra were recorded by using a Perkin-Elmer Spectrum GX. Microanalyses were performed by using a Perkin-Elmer elemental analyzer 2400, Series II. The singlecrystal X-ray diffraction data were recorded by using a BRUKER AXS, SMART APEX II (CCDC No 776092).

\subsection{Preparation of Salts}

L-Valine methyl ester hydrochloride was purchased from Aldrich. The free amino acid methyl ester was prepared by treating the aqueous solution of this hydrochloride salt with an aqueous solution of $\mathrm{K}_{2} \mathrm{CO}_{3}(2.0 \mathrm{M})$ followed by extraction in the diethyl ether layer. In the next step, the ether extract was dried over anhydrous $\mathrm{Na}_{2} \mathrm{SO}_{4}$. The organic layer containing the free valine methyl ester was then reacted with p-methyl cinnamic acid, and an aspirator pump removed the solvent. The resultant salt (supramolecular container of pheromone) was subjected to various physicochemical analyses. In similar way, L-leucine methyl ester hydrochloride, L-isoleucine methyl ester hydrochloride, L-phenylalanine methyl ester hydrochloride can be reacted with p-methyl cinnamic acid for preparing a series of pheromone container salts. ${ }^{[4]}$

\subsection{Preparation of Microcrystals}

L-Valine methyl ester p-methyl cinnamate salt was dissolved in dry diethyl ether. The ether was allowed slowly to evaporate for developing long needle-shaped micro-thin crystals under the $\mathrm{N}_{2}$ atmosphere. Instead of dry ether, dry hexane can also be used for crystallization.

\subsection{Preparation of Single crystal}

To demonstrate the supramolecular channel inside the needle crystals, valine methyl ester p-methyl cinnamate salt was subjected to crystallize in various solvents. However, it only crystallized in Hexane/ $\mathrm{CHCl}_{3}$ solution, where the supramolecular channel could be visualized. Inside the supramolecular channel, the $\mathrm{CHCl}_{3}$ was trapped (Fig. 4e). Generally, the water channel is formed inside DNA-strand, microtubule, but here water kicks out the volatile amine part from the crystals. Theoretically, inside the supramolecular channel, it is established that when a single water molecule arrives, the pheromone gets released.

\subsection{NMR study}

The salt was kept in a Petri dish in the open air for 45 days, and a little from the bulk was keep on taking for timedependent NMR study. The temperature $\left(26-35{ }^{\circ} \mathrm{C}\right)$ and humidity $(58-94 \%)$ fluctuated during the time-dependent pheromone release study. The immediate NMR study was performed in $\mathrm{CDCl}_{3}$ after collecting the sample from the Petry dish. Here solid-state NMR ${ }^{[25]}$ study is not essential.

\subsection{Computational Section}

The $a b$ initio calculations were performed using the Gaussian o9 package ${ }^{[26]}$ version D.01 at the B3LYP/6-31++G $(\mathrm{d}, \mathrm{p})$ level. The diffuse functions in the basis set are included to treat transfers involving balanced anionic species. The linear proton transfer situation is considered as the most energetically facile and implemented using suitable constraints in Molecular Mechanics Force Field (MMFF94) optimization ${ }^{[27]}$ in Avogadro molecule editor.

\subsection{Physico-chemical Characterization}

Valinemethylester p-methylcinnamate: $\mathrm{mp} .117-122^{\circ} \mathrm{C}$, Anal. Calc. For $\mathrm{C}_{16} \mathrm{H}_{23} \mathrm{NO}_{4}$ : C, 65.51; H, 7.90; N, 4.77. Found: C, 65.28; H, 7.73; N, $4.73 \%$. FT-IR (KBr): 3471, 2967, 2361, 2144, 1745, 1642, 1514, 1441, 1377, 1286, 1260, 1205, 1110, $1051,991,882,851,821,776,747,707,526,496,431 \mathrm{~cm}^{-1}$. ${ }^{1} \mathrm{H} \mathrm{NMR}\left(\mathrm{CD}_{3} \mathrm{OD}\right)(200 \mathrm{MHz}) \delta=7.556-7.421(\mathrm{~m}, 3 \mathrm{H}), 7.212-$ $7.174(\mathrm{~m}, 2 \mathrm{H}), 6.426\left(\mathrm{~d}, \mathrm{~J}=16.0 \mathrm{~Hz}, 1 \mathrm{H}, \mathrm{CHCOO}^{-}\right), 3.791(\mathrm{~s}$, $\left.3 \mathrm{H}, \mathrm{OCH}_{3}\right), 3.654\left(\mathrm{~m}, 1 \mathrm{H},{ }^{+} \mathrm{NH}_{3} \mathrm{CH}\right), 2.344\left(\mathrm{~s}, 3 \mathrm{H}, \mathrm{p}-\mathrm{CH}_{3}\right)$, 2.175- $2.114\left(\mathrm{~m}, 1 \mathrm{H}, \mathrm{CHMe}_{2}\right), 1.026(\mathrm{~d}, \mathrm{~J}=1.60 \mathrm{~Hz}$, $\left.\mathrm{CHMeCH}_{3}\right), 0.991\left(\mathrm{~d}, \mathrm{~J}=1.60 \mathrm{~Hz}, \mathrm{CHMeCH}_{3}\right)$.

\subsection{Theoretical studies}

All the four stages of the salt to free acid-amine were optimized (I through IV) by Merck Molecular Force Field (MMFF94) in the present work. For each of the optimized structures, single-point energy was computed at the secondorder Moller-Plesset (MP2) level with Gaussian 0914 using 6$31++\mathrm{G}(\mathrm{d}, \mathrm{p})$ as the basis set (Table 3). The ab initio calculations were performed using the Gaussian o9 package version D.01 at the MP2/6-31++G (d, p) level.

\section{Results and discussion. \\ 3.1 NMR Kinetic Studies}

To check the time-dependent release of valinemethyl ester, $200 \mathrm{mg}$ of valine methyl ester p-methylcinnamate salt was taken in a Petri dish and kept uncovered. The 1H NMR was conducted in the $\mathrm{CDCl}_{3}$ solution to check the release of volatile valinemethyl ester against time. ${ }^{[4]}$ It is interesting to note that the peak at $\delta=3.74$ is slowly disappearing with time following first-order rate law, $\ln [\mathrm{A}]=\ln [\mathrm{A}]_{0}-\mathrm{kt}$, where $[\mathrm{A}]_{0}$ is the initial concentration of the salt, $[\mathrm{A}]$ is the concentration at time $\mathrm{t}$ (in days) (Fig. 1c and Fig. 1d). After a water-driven proton displacement reaction, the water molecule either passes to the air or gets adsorbed again on the newly exposed solid surface. The increase in humidity makes the release rate a little 
faster, reflecting the fluctuation of the data points in NMR monitoring. The faster release of pheromone on humid days makes the point slightly lower than the average value in this graph. Optical polarizing microscopic study showed that the crystalline fibers lose the birefringence and slowly in air converted into amorphous p-methyl cinnamic acid (Fig. 1e and Fig.1f), which was further supported by IR and NMR spectroscopy. In a separate UV spectroscopy experiment, it was found that dissolving the compound in a protic solvent $(\mathrm{MeOH})$ can release the entire volatile ammonium part within a few minutes. After complete release of pheromones, the compound left at petridish is only p-methyl trans cinnamic acid, which is confirmed by the IR experiment. The IR spectra of this salt residue exactly matches with pure trans isomer of p-methyl cinnamic acid. However, after releasing the pheromone, the crystals or crystalline fibers of the salt become completely amorphous and can not be picked up even as a crystal for X-ray diffraction. In PXRD, no characteristic peak of salt or even p-methyl trans cinnamic acid is observed.

\subsection{Analysis of PAM Synthon by DFT}

Quantum chemical methods such as DFT (Density Functional Theory) allow one to determine the ground state electronic structure of a molecule in a vacuum and condensed phases like solution and crystal. In many instances, amino acids like alanine are in molecular form in the vacuum but stable in the salt form in the crystal. Therefore, DFT is widely used to assess the thermodynamic stability in the solid-state and solution.

On optimizing the molecular structure before and after proton transfer at $\mathrm{B} 3 \mathrm{LYP} / 6-31++\mathrm{G}(\mathrm{d}, \mathrm{p})$ level, one gets the molecular structures shown in Figs. 2a and 2b. In Fig. 2a, the optimized distance between the donor oxygen and acceptor nitrogen before proton transfer is $2.691 \AA$, and the same after proton transfer is $2.681 \AA$, as shown in Tables 2 and 3. The energy difference is $\sim 7 \mathrm{~kJ} / \mathrm{mole}$, with the structure shown in Fig. $2 b$ having less energy. However, this structure is hugely distorted and tends towards the structure shown in Fig. 2a, which is more stable in a vacuum. The structures are shown in Fig. $2 \mathrm{a}$, and $2 \mathrm{~b}$ are very similar, $\mathrm{O}-\mathrm{H} \cdots \mathrm{N}$ sequence in the former changing to $\mathrm{O} \cdots \mathrm{H}-\mathrm{N}$ in the latter in a linear fashion (highlighted with dotted yellow straight lines). The interesting point is that an asymmetric structure (with little charge delocalization on carboxylate results, rather than the more symmetric structure with full charge delocalization on carboxylate,) is predicted by Merck Molecular Force Field (MMFF) optimization (Fig. 2c).

Table 2. Optimization before Proton Transfer in Vacuum (Fig.

2a).

\begin{tabular}{cccc}
\hline $\begin{array}{l}\text { N-O }(\mathrm{D}-\mathrm{A}) \\
\text { Distance }(\AA)\end{array}$ & $\begin{array}{l}\text { O-H Bond } \\
\text { Distance }(\AA)\end{array}$ & $\begin{array}{l}\mathrm{N} \cdots \mathrm{H} \\
\text { Distance }(\AA)\end{array}$ & $\begin{array}{c}\mathrm{O}-\mathrm{H} \cdots \mathrm{N} \\
\text { Angle }\left(^{\circ}\right)\end{array}$ \\
\hline 2.691 & 1.027 & 1.68548 & 177.9 \\
\hline
\end{tabular}

The force field method is not as reliable as the DFT in locating the ground state electronic structure. Interestingly, there are two charge-assisted $\mathrm{H}$-bonds and no distortions in $\mathrm{N}$ $\mathrm{H}$ bond distances in Fig. 2c, yet it is not as stable as the structure shown in Fig. 2a. A DFT optimization, starting from Fig. 2c, converges to Fig. 2b, confirming that the structure shown in Fig. 2a is the ground state, as per our arguments given above. Table 4 is summarized the relevant bond lengths and bond angles of the structure shown in Fig. 2c. The HNH bond angle departs much from the tetrahedral angle of $109.5^{\circ}$. $\mathrm{N}-\mathrm{H} \cdots \mathrm{O}$ angles of 141.7 and 139.9 depart much from the ideal H-bond angle of 180 , as pointed out by Pauling. These departures cause strain, which does not allow the structure in Fig. $2 \mathrm{c}$ to be the ground state. However, the molecular salt form is stable in n-clusters with $\mathrm{n}>2$, realizable in $\mathrm{CHCl}_{3}$ solutions, and in crystals, as shown below. This is because the structural constraints can easily be met in those situations.

Table 3. Optimization after Proton Transfer in Vacuum (Fig. 2b).

\begin{tabular}{llll}
\hline $\mathrm{N}-\mathrm{O}(\mathrm{D}-\mathrm{A})$ & $\mathrm{O}-\mathrm{H} \quad \begin{array}{c}\text { Bond } \\
\text { Distance }(\AA)\end{array}$ & $\begin{array}{l}\mathrm{N} \cdots \mathrm{H} \\
\text { Distance }(\AA)\end{array}$ & $\begin{array}{l}\mathrm{O}-\mathrm{H} \cdots \mathrm{N} \\
\text { Distance }(\AA)\end{array}$ \\
\hline 2.681 & 1.01933 & 1.653 & 174.8 \\
\hline
\end{tabular}

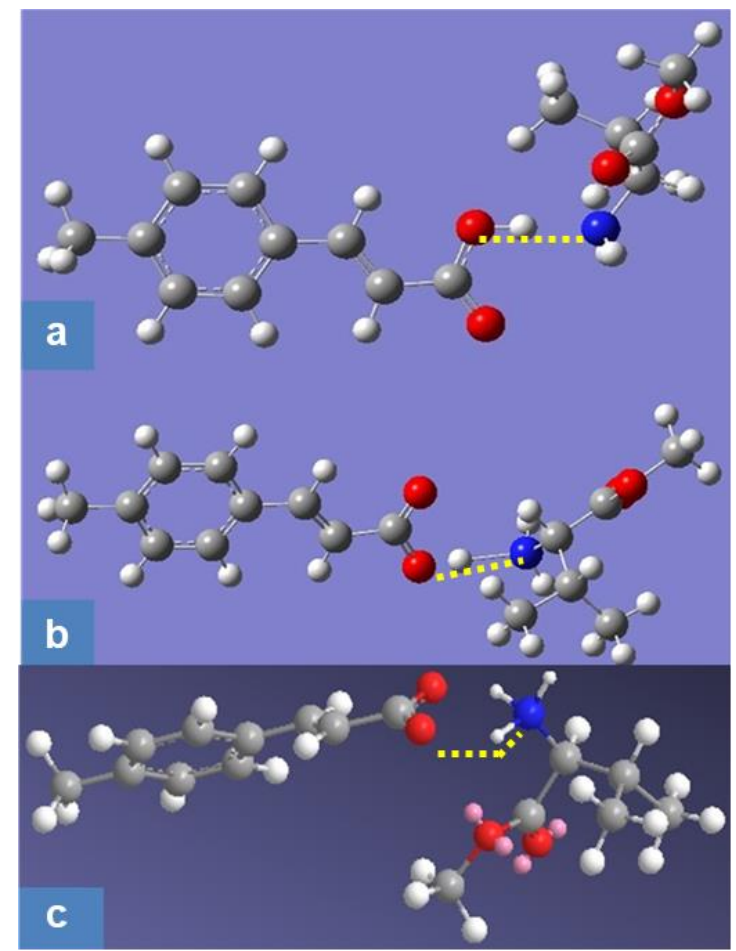

Fig. 2 (a) Valine methyl ester and p-methylcinnamic acid molecules after optimization at B3LYP/6-31++G(d,p) level. Hbond: $\mathrm{N}$ (blue) - $\mathrm{H}$ (white)- $\mathrm{O}$ (red) sequence is linear (highlighted by yellow dotted line). (b) 4-methyl valinium pmethylcinnamate molecule after optimization at B3LYP/6$31++\mathrm{G}(\mathrm{d}, \mathrm{p})$ level. Charge-assisted H-bond: N-H-O sequence is linear (highlighted by yellow dotted line). (c) Bound state after proton transfer, predicted by MMFF94, shows full charge delocalization on carboxylate group and a symmetric structure with two charge-assisted H-bonds. Herein, $\mathrm{O}, \mathrm{H}$ and $\mathrm{N}$ are nor arranged in an angular way (highlighted by yellow dotted angle). 
Table 4. Characteristics of the MMFF optimized structure in Fig. 2c.

\begin{tabular}{ccccccc}
\hline $\begin{array}{c}\mathrm{N}-\mathrm{H} \text { bond } \\
\text { length }(\AA)\end{array}$ & $\begin{array}{c}\mathrm{C}-\mathrm{O} \text { bond } \\
\text { length }(\AA)\end{array}$ & $\begin{array}{c}\mathrm{O} \text { to } \mathrm{O} \\
\text { distance }(\AA)\end{array}$ & $\begin{array}{c}\mathrm{N}-\mathrm{H} \cdots \mathrm{O} \\
\text { distance }(\AA)\end{array}$ & NHO angle $\left({ }^{\circ}\right)$ & OCO angle $\left({ }^{\circ}\right)$ & $\begin{array}{c}\mathrm{HNH} \\
\text { angle }\left({ }^{\circ}\right)\end{array}$ \\
\hline $1.051,1.050$ & $1.267,1.270$ & 2.218 & $2.488,2.531$ & $141.7,139.9$ & 122 & 96.7 \\
\hline
\end{tabular}
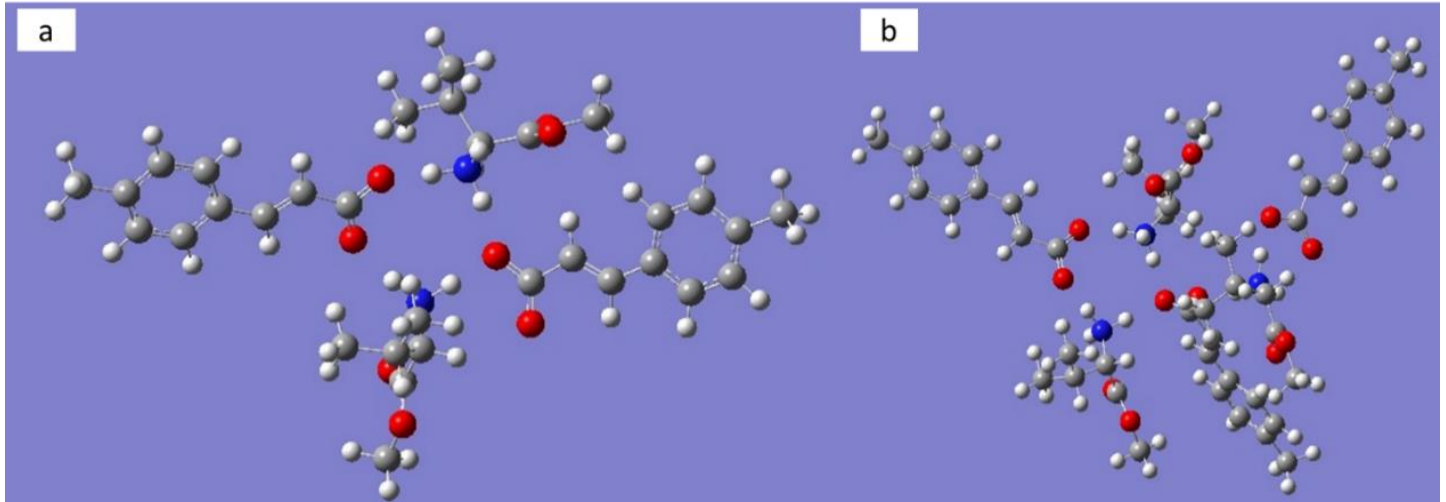

Fig. 3 (a). 2-molecule cluster after proton transfer in $\mathrm{CHCl}_{3}$. (b). 3-molecule cluster after proton transfer in $\mathrm{CHCl}_{3}$.

In aprotic solvents like chloroform, the formation of the salt molecular form is again impossible, as is evident from an inspection of Tables 6 and 7. The structure indicated by Table 7 corresponds to salt molecular form, which shows a slightly lower energy than that indicated by Table 6 . However, because of an inordinately large N-H bond distance, the salt molecular form is inadmissible. DFT studies of 2- molecule and 3molecule clusters were also carried out at the B3LYP/6$31++(\mathrm{d}, \mathrm{p})$ level, with results being displayed in Figs. 3a and3b, respectively. The relevant characteristics of the chargeassisted H-bonds shown in Figs. $3 \mathrm{a}$ and $3 \mathrm{~b}$ are recorded in Tables 5 and 8 . The $\mathrm{N}-\mathrm{H}$ bond lengths in Tables 5 and 8 agree with the literature values. $\mathrm{N}-\mathrm{H} \cdots \mathrm{O}$ angles, varying between 160 and 178, agree with those reported for crystal and pretty close to Pauling's value of $180^{\circ}$. The HNH bond angles are close to tetrahedral value.

Table 5. Optimization in 2-molecule cluster after Proton Transfer in $\mathrm{CHCl}_{3}$ (Fig.3a).

\begin{tabular}{ccclc}
\hline $\begin{array}{c}\mathrm{N}-\mathrm{O}(\mathrm{D}- \\
\mathrm{A})\end{array}$ & $\begin{array}{c}\mathrm{N}-\mathrm{H} \\
\text { Distance } \\
\begin{array}{c}\text { Distance } \\
(\AA)\end{array}\end{array}$ & $\begin{array}{c}\mathrm{O} \ldots \mathrm{H} \\
\text { Bond }\end{array}$ & $\begin{array}{c}\mathrm{N}-\mathrm{H} \cdots \mathrm{O} \\
\text { Angle }\left(^{\circ}\right)\end{array}$ & $\begin{array}{c}\mathrm{H}-\mathrm{N}-\mathrm{H} \\
\text { bond } \\
\text { angle }\left(^{\circ}\right)\end{array}$ \\
\hline 2.667 & 1.073 & 1.610 & 167.1 & 106.7 \\
2.708 & 1.058 & 1.668 & 166.6 & \\
2.692 & 1.070 & 1.622 & 177.3 & 107.3 \\
2.750 & 1.052 & 1.717 & 166.3 & \\
\hline
\end{tabular}

Table 6. Optimization before proton transfer in $\mathrm{CHCl}_{3}$ solution.

\begin{tabular}{clll}
\hline N-O $(\mathrm{D}-\mathrm{A})$ & O-H Bond & $\mathrm{N} \cdots \mathrm{H}$ & $\mathrm{O}-\mathrm{H} \cdots \mathrm{N}$ \\
Distance $(\AA)$ & Distance $(\AA)$ & Distance $(\AA)$ & Angle $\left({ }^{\circ}\right)$ \\
\hline 2.698 & 1.025 & 1.68548 & 177.1 \\
\hline
\end{tabular}

Table 7. Optimization after proton transfer in $\mathrm{CHCl}_{3}$ solution.

\begin{tabular}{llll}
$\mathrm{N}-\mathrm{O}(\mathrm{D}-\mathrm{A})$ & $\mathrm{O}-\mathrm{H} \quad$ Bond & $\mathrm{N} \cdots \mathrm{H}$ & $\mathrm{O}-\mathrm{H} \cdots \mathrm{N}$ \\
Distance $(\AA)$ & Distance $(\AA)$ & Distance $(\AA)$ & Angle $\left(^{\circ}\right)$ \\
\hline 2.691 & 1.027 & 1.68548 & 177.9 \\
\hline
\end{tabular}

The standard-state free energy of solvation is the free energy of transfer from the gas phase to the condensed (solution) phase under standard-state conditions, e.g. $1 \mathrm{~mole} / \mathrm{L}$ in both the phases, and can be partitioned according to

$$
\Delta G^{0}=\Delta G_{N E P}+G_{C D S}
$$

The first term on the right-hand side of Eq. (1) can be further partitioned into a nuclear relaxation term $\left(\Delta G_{N}\right)$ and an electronic polarization term $\left(\Delta G_{E P}\right)$. The nuclear relaxation contribution to the free energy is equal to the difference between the gas-phase total energy calculated at gas-phase equilibrium structure and the total energy calculated at liquidphase equilibrium structure. In the present case the gas-phase and the liquid-phase structures differ by reason of a proton transfer in the latter. Two separate molecules in the gas-phase becomes one salt molecule in the liquid (solution) phase. The self-consistently determined interaction between the solute charge distribution and the electric polarization of the solvent, when adjusted for the energetic cost of polarizing the solute and the solvent, constitutes the electronic polarization contribution to the free energy. The calculation of this term involves the solution of the nonhomogeneous Poisson equation for electrostatics in terms of the integral-equationformalism polarizable continuum model (IEF-PCM). The second term on the right-hand-side of Eq. (1) is attributed to cavity-dispersion-solvent structure and arises from the solutesolvent short-range interactions in the first solvation shell. This contribution is a sum of terms that are products of atomic surface tensions and the solvent-accessible areas of individual atoms of the solute. The solvation model density (SMD) 
Table 8. Optimization in 3-molecule cluster after proton transfer in $\mathrm{CHCl}_{3}$ (Fig. 3b).

\begin{tabular}{|c|c|c|c|c|}
\hline $\begin{array}{l}\text { N-O }(\mathrm{D}-\mathrm{A}) \\
\text { Distance }(\AA)\end{array}$ & N-H Distance $(\AA)$ & $\begin{array}{c}\text { O } \cdots \text { H Bond } \\
\text { Distance }(\AA)\end{array}$ & $\mathrm{N}-\mathrm{H} \cdots \mathrm{O}$ Angle $\left({ }^{\circ}\right)$ & $\begin{array}{c}\mathrm{H}-\mathrm{N}-\mathrm{H} \text { bond angle } \\
\left(\left(^{\circ}\right)\right.\end{array}$ \\
\hline 2.747 & 1.068 & 1.627 & 171.0 & 107.5 \\
\hline 2.728 & 1.061 & 1.676 & 170.2 & \\
\hline 2.687 & 1.058 & 1.690 & 176.9 & 106.7 \\
\hline 2.755 & 1.051 & 1.710 & 172.1 & \\
\hline 2.813 & 1.042 & 1.797 & 163.9 & 109.8 \\
\hline 2,618 & 1.094 & 1.540 & 166.9 & \\
\hline
\end{tabular}

method-implemented on Gaussian 09 computational chemistry programme - is used to calculate the standard-state free energy of solvation with electronic structure method B3LYP/6-31++ (d, p) in chloroform solvent. ${ }^{[28]}$

In order to envisage the supramolecular channel, we have tried to crystallize the salt in presence of several aprotic solvent and at last it crystallized out from hexane: $\mathrm{CHCl}_{3}(50$ : 50) mixture where the chloroform molecules (Fig. 4e) occupied the supramolecular channel. It crystallized out in orthorhombic non-centrosymmetric P $2{ }_{1} 2{ }_{1} 2_{1}$ space group. ${ }^{[4]}$ The asymmetric unit contains one carboxylate, one ammonium and one chloroform moieties each. In the crystal structure, each carboxylate moiety is involved in hydrogen bonding with three ammonium moieties via $\mathrm{N}^{+}-\mathrm{H}^{\cdots} \mathrm{O}^{-}$ interactions $\left(\mathrm{N} \cdots \mathrm{O}=2.722(6)\right.$ - 2.752(6) $\AA, \angle \mathrm{N}^{+}-\mathrm{H}^{\cdots} \mathrm{O}^{-}=$ $\left.152.3-169.3^{\circ}\right)$ and propagates along the crystallographic $a$ axis to form PAM synthon (Fig. 1a). While propagating, the voidspace appears along a axis as well and the guest $\mathrm{CHCl}_{3}$ molecules fits inside this supramolecular channel. The two carbon-oxygen bonds in the carboxylate group of the cinnamate moiety are of nearly equal length $(1.25 \AA)$ because of charge delocalization (Fig. 3b).

Under normal conditions of temperature and pressure, $\mathrm{p}$ methyl cinnamic acid is a molecular solid (Fig. 1f), whereas valine methyl ester exists in the vapour state. ${ }^{[4]}$ In the salt crystalline state, the positively charged nitrogen atom has three attached protons to participate in H-bonding with three different carboxylate groups, each with oxygen atoms carrying partial negative charges, as shown in Fig. 1a and discussed in the preceding paragraph. Conversely, each negatively charged carboxylate group engages in H-bonding with three different ammonium moieties (Fig. 1a). Each of these charge-assisted $\mathrm{H}$-bonds is considerably stronger than ordinary $\mathrm{H}$-bonds with no charge involvements. ${ }^{[29]}$ In fact, directional N-H $\cdots \mathrm{O}$ and O$\mathrm{H} \cdots \mathrm{O}$ bonds reinforced by charge-assistance have been used to synthesise whole new families of organic-organometallic supramolecular salts. ${ }^{[30]}$

\subsection{Heterogeneous Catalysis Model of Disintegration}

As already pointed out, the molecular salt form is not stable in protic solvents such as water and alcohol. However, water molecules can interact in a controlled fashion with the molecular salt form in a chloroform medium. Investigation of such a situation has been carried out at the B3LYP/6-31++(d, p) level. The optimization result is shown in Fig. 3a, with the geometry around the interaction zone recorded in Table 9. The calculation used the SMD method of Truhlar et al. ${ }^{[31]}$ and the Mod Redundant option of Gaussian 09, as previously introduced. As a result, the water molecule (in the foreground in Fig. 3a) positions itself such that $\mathrm{H}$-bonded interactions: $\mathrm{O}$ (water)-H-N(primary ammonium) and O(water)-H$\mathrm{O}($ cinnamate) can take place. Thus, water $(\mathrm{pK}=14)$ can abstract a proton from the primary ammonium ion and give a proton to the cinnamate ion, thereby effecting a proton transfer via a transition state mechanism.

If a reaction occurs through these steps:

$$
\mathrm{A}(\mathrm{s})+\mathrm{B}(\mathrm{g}) \rightleftharpoons \mathrm{AB}(\mathrm{s}) \rightarrow \text { Products, }
$$

where $B$ is the catalyst in the gas phase (e.g. moist air), and A is both an adsorption site and the reactant on the solid surface, and the respective rate constants for the adsorption, desorption, and reaction are $\mathrm{k}_{1}, \mathrm{k}_{-1}$, and $\mathrm{k}_{2}$, then the global reaction rate is:

$$
r=-\frac{d N_{A}}{d t}=k_{1}(1-\theta) N_{A} C_{B}-k_{-1} N_{A B},
$$

$\mathrm{N}_{\mathrm{AB}}$ is the number of occupied sites on the surface; $\theta$ is the surface coverage, dimensionless; $\mathrm{N}_{\mathrm{A}}$ is the total number of surface sites (occupied or not), and t is time. Clearly,

$$
N_{A B}=\theta N_{A}
$$

If we apply the steady-state approximation to $\mathrm{AB}$, then:

$$
\frac{d N_{A B}}{d t}=0=k_{1} C_{B} N_{A}(1-\theta)-k_{2} \theta N_{A}-k_{-1} \theta N_{A},
$$

yielding

$$
\theta=\frac{k_{1} C_{B}}{k_{1} C_{B}+k_{-1}+k_{2}}
$$

Then, using Eqs. (1), (2), and (4), we get

$$
r=-\frac{d N_{A}}{d t}=\frac{k_{1} k_{2} N_{A} C_{B}}{k_{1} C_{B}+k_{-1}+k_{2}}
$$

The rate equation is complex, and the reaction order is not clear. In experimental work, usually, two extreme cases are looked for in order to prove the mechanism. In them, the ratedetermining step can be either of the following:

Limiting Step: Adsorption/Desorption

$$
k_{2} \gg k_{1} C_{B}, k_{-1} \text {, so } r \approx k_{1} N_{A} C_{B}
$$

The order concerning $\mathrm{A}$ is 1 , and that for $\mathrm{B}$ is also 1 . Thus, the overall order is 2 .

Limiting Step: Reaction

$$
k_{2} \ll k_{1} C_{B}, k_{-1} \text {, so } \theta \approx \frac{k_{1} C_{B}}{k_{1} C_{B}+k_{-1}},
$$

which is just the Langmuir isotherm

$$
r=\frac{K_{1} k_{2} N_{A} C_{B}}{K_{1} C_{B}+1}
$$


a
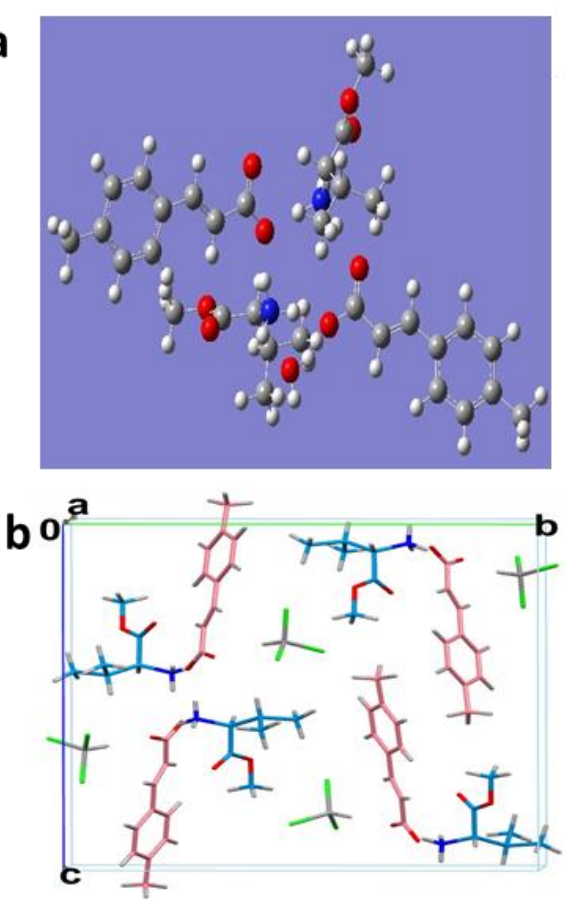
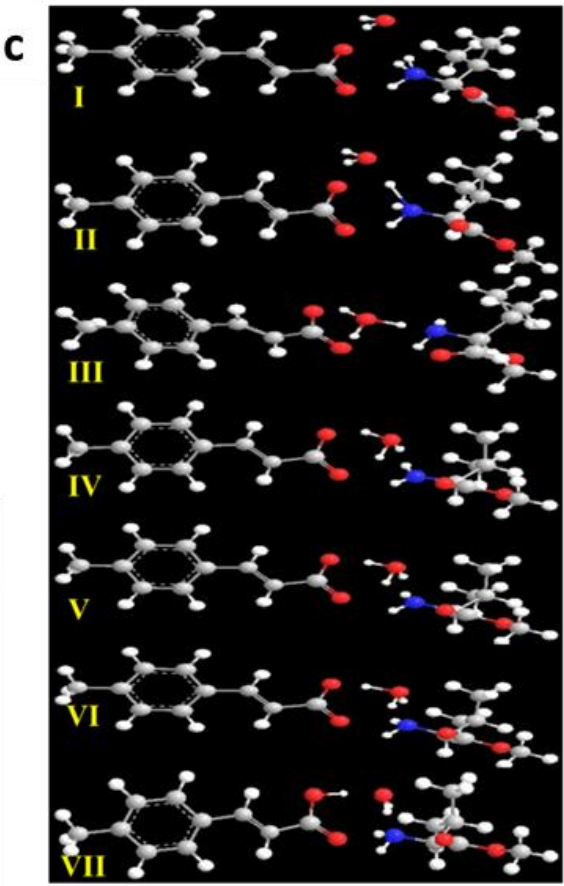

d

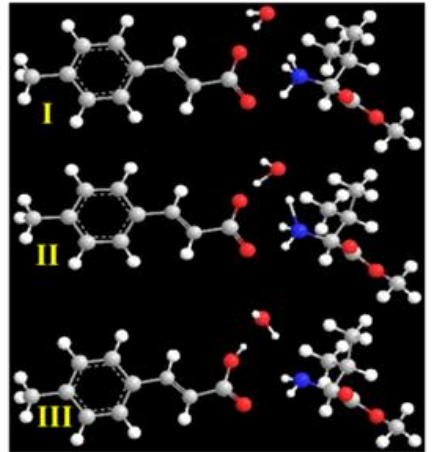

e

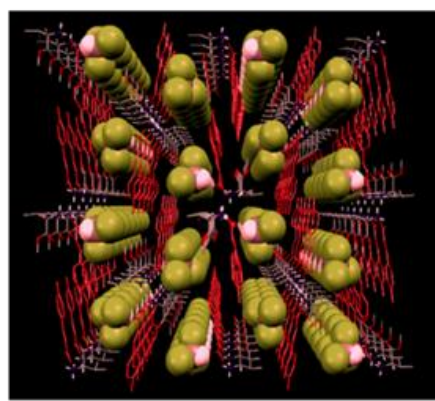

Fig. 4 (a). Interaction of the water molecule (foreground) with a 2-molecule salt cluster in chloroform medium. (b). Unit cell structure of valine methyl ester p-methylcinnamate crystal. Four unit cells are shown. The $\mathrm{CHCl}_{3}$ molecules are trapped inside the supramolecular channel. The $\mathrm{a}=6.1743 \AA$ axis is perpendicular to the plane of the paper, $b=18.277 \AA$ is along the width and $\mathrm{c}=$ $18.664 \AA$ is along the length of paper to define a right-handed system. The space group is P2 $2_{1} 2_{1} 2_{1}$. (c). Two-step Proton transfer illustrated with MMFF94 optimization. I) one water molecule occupying a channel of the salt; II) transfer proton to $\mathrm{N}$ bond vibrationally stretched to $1.75 \AA$; III) proton subject to transfer gets bonded to the oxygen of water at a distance of $1.75 \AA$; IV) Amine liberated and dissociated 4-methyl cinnamic acid forms; V) proton bonded to water oxygen becomes linear with the former and the carboxylate oxygen; VI) the proton to water oxygen bond stretches to 1.20 A (O-O distance: $2.40 \AA$ ); VII) Proton transfer to carboxylate anion takes place liberating water. (d). One-step proton transfer illustrated with MMFF94 optimization. Panel I represents $\mathrm{N}-\mathrm{H} 1$ and $\mathrm{O}-\mathrm{H} 2$ protons at their normal bond distances. Panel II represents a transition state with both bonds vibrationally stretched to the midpoints of respective donor-acceptor (DA) distances. Panel III gives the final situation. (e). Crystal structure of valine methyl ester p-methylcinnamate. The $\mathrm{CHCl}_{3}$ molecules are trapped inside the supramolecular channel.

Table 9. Geometry around the Water-Salt Interaction Zone.

\begin{tabular}{ccccc}
\hline $\begin{array}{c}\mathrm{H}_{2} \mathrm{O}-\mathrm{O}(\mathrm{Cinn}) \\
\text { Distance }(\AA)\end{array}$ & $\begin{array}{c}\mathrm{HO}-\mathrm{H} \cdots \mathrm{O}(\mathrm{Cinn}) \\
\text { Angle }\left({ }^{\circ}\right)\end{array}$ & $\begin{array}{c}\mathrm{H}_{2} \mathrm{O}-\mathrm{N}(\text { Ammon }) \\
\text { Distance }(\AA)\end{array}$ & $\begin{array}{c}\mathrm{H}_{2} \mathrm{O} \cdots \mathrm{H}-\mathrm{N}(\text { Ammon }) \\
\text { Angle }\left(^{0}\right)\end{array}$ & $\begin{array}{c}\text { (Cinn)O-N(Ammon) } \\
\text { Distance }(\AA)\end{array}$ \\
\hline 2.7172 & 155.381 & 2.9777 & 127.463 & 2.7445 \\
\hline
\end{tabular}

$$
\text { with } K_{1}=k_{1} / k_{-1} \text {, }
$$

Depending on the concentration of the catalyst the rate changes:

For low concentrations of $\mathrm{B}$, then

$$
r=K_{1} k_{2} N_{A} C_{B},
$$

That is to say a first order reaction in component $\mathrm{A}$, and first order in component $\mathrm{B}$, i.e. overall order is 2 .

For high concentrations of $\mathrm{B}, r=k_{2} N_{A}$,

that is, first order with respect to $A$ and zero order with respect to $\mathrm{B}$, which implies that the overall order is 1 .

Thus, an overall first order kinetic behaviour is possible when the water molecule concentration in moist air is large compared to the surface concentration of reactant molecules, and the rate-determining step is attributable to chemical reaction. These conditions may be met in a vapour-solid heterogeneous catalysis reaction.

An optimization at $\mathrm{HF} / 6-31(\mathrm{~d}, \mathrm{p})$ level gives the structure shown in Fig. 3. The charge-assisted H-bonds in the crystal are replaced by charge-assisted $\mathrm{H}$-bonds involving water. ${ }^{[32]}$

The proton transfer takes place from nitrogen to water oxygen based on a large $\Delta \mathrm{p} K_{a}=6.05-15.7=-9.65$. This leads to the liberation of valine methyl ester as a gas. $\mathrm{H}_{3} \mathrm{O}^{+}(\mathrm{p}-$ methylcinnamate) that is left undergoes a second proton transfer $\left(\Delta \mathrm{p} K_{a}=-1.74-9.44=-11.18\right)$ to release water and yield the corresponding acid as a solid material.

\subsection{Crystal Engineering Strategy}

As we have seen, $\Delta \mathrm{pKa}$ bears a roughly linear relation to $\mathrm{E}_{12}$ (Fig. 2). The latter determines the lattice energy of the molecular crystal: 


$$
E_{\text {lattice }}=-\Delta H_{\text {sub }}-2 R T+E_{12} \text {, }
$$
If $\Delta \mathrm{pKa}$ is small, negative, or positive, $\mathrm{E}_{12}$ is a moderate energy term, making the lattice energy substantial. It would allow the use of the material as a supramolecular container. The former is large. The latter should also be large, making dispersion forces and $\mathrm{H}$-bonds unable to stabilize a crystalline state. If $\Delta \mathrm{pKa}$ and $\mathrm{E}_{12}$ are small or negative, the crystalline state could realize but may end up yielding a gel, rather than separated reactants, in the presence of a protic solvent. Therefore, an optimum $\Delta \mathrm{pKa}$ and $\mathrm{E}_{12}$ are needed so that supramolecular crystal forms and reactants appear in the presence of a protic solvent. If the $\Delta \mathrm{pKa}$ values of salts become higher to 3.6 and amines are not volatile, the reactants will not produce any labile materials. ${ }^{[3,34]}$

However, they will generate gelling or non-gelling supramolecular organic salts. ${ }^{[35-39]}$ Besides the $\Delta \mathrm{pKa}$ value in selecting acid and base, one of the most important things is selecting supramolecular synthon. As the pheromones are volatile, we need to select the carboxylic acid, which will form Co-crystal ${ }^{[40-42]}$ or weak salts where the $\Delta \mathrm{pKa}$ value will not cross 3.6 and, importantly, it should be monocarboxylic acids. In dicarboxylic acid-forming primary ammonium dicarboxylate (PAD) synthon, the crystals often pack in 2D architecture and do not release amine even in protic solvent. [43] However, Cinnamic acid moiety always promotes supramolecular devices in keeping the amine part labile, but benzoic acid moiety fails to do it. ${ }^{[44]}$ This additional molecular length of cinnamic acid compared to benzoic acid promotes void formation in the crystal lattice, which invites water as a guest molecule and releases the amine via exchanging the proton.

\subsection{Precaution at pheromone release for trapping the pests 3.5.1 Preserving pheromone container at home}

As the moisture is very natural element in air and increases with rain, so keeping the pheromone container salt in an open atmosphere will release the pheromone spontaneously. To stop the pheromone release, one needs to preserve the pheromone container in an air tight vial and preferably should preserve the vial at normal domestic refrigerator.

\subsubsection{Using at cultivation field}

The supramolecular container releases the amine molecule (pheromone) slowly to the environment, similar to the female Phyllophaga species to attract the male counterparts. However, the Phyllophaga species release a set of aminoacid methyl esters, ${ }^{[3,5,6]}$ like phenylalanine methyl ester, valine methyl ester. Isoleucine methyl ester or leucine methylester in a certain ratio. Hence, according to the ratio, farmer needs to take the different pheromone containers and mixed it before keeping it in a physical trap. The trap will be like a wood or plastic made trap, where in male insect can enter, but cannot exit. This trap will also protect the supramolecular salts from external waters in liquid form (rain, dew). After releasing the pheromone, $\mathrm{p}$ methyl cinnamic acid can be re used. It is an eco-friendly chemical and will not introduce any chemical pollution in environment.

\section{Conclusions}

A supramolecular container containing PAM synthon may function as a green pest control device. This device can be prepared if the PAM salts can be crystallized in aprotic solvents like diethyl ether, hexane by slow evaporation method in growing microthin needle-shaped crystal. The moisture transfers the proton from ammonium to carboxylate moiety in such microthin crystals and promotes the microcrystals as a supramolecular pheromone releasing device. This moisture-driven pheromone releasing process maintains the first-order kinetics, which can capture a series of Phyllophaga pests in a greenway. Even in the nominal presence of water as in moist air, the crystal lattice is unstable against disintegration into molecular ionpairs, which in their turn are unstable against disintegration into individual molecules. Such a supramolecular container can be a real solution to the unwanted use of pesticides against phyllophaga pests.

\section{Acknowledgements.}

PS acknowledges Bose Institute, India and NIMS, Japan for providing the research facility. We also acknowledge Dr. Partha Pratim Bag (SRM University) for his deep support.

\section{Conflict of interest}

There are no conflicts to declare.

\section{Supporting information}

Not applicable.

\section{References}

[1] S. R. Jadhav, B.-S. Chiou, D. F. Wood, G. DeGrande-Hoffman, M. Glenn, G. John, Soft Matt., 2011, 7, 864-867, doi: 10.1039/COSM00878H.

[2] C. A. Atterholt, M. J. Delwiche, R. E. Rice, J. M. Krochta, J. Control. Release, 1999, 57, 233-247, doi: 10.1016/S01683659(98)00119-9.

[3] A. Zada. L. Falach, J. A. Byers, Chemoecology, 2009, 19, 37-45, doi: 10.1007/s00049-009-0007-9.

[4] P. Sahoo, D. Krishna Kumar, S. R. Raghavan, P. Dastidar, Chem. Asian J., 2011, 6, 1038-1047, doi: 10.1002/asia.201000560.

[5] Y. Wang, O. Zeiri M. Raula, B. Le Ouay, F. Stellacci, I. A. Weinstock, Nat. Nanotechnol., 2017, 12, 170-176, doi: 10.1038/nnano.2016.233.

[6] E. A. Andreyko, P. L. Padnya, R. R. Daminova, I. I. Stoikov, RSC Adv., 2014, 4, 3556-3565, doi: 10.1039/C3RA44052D.

[7] S. P. Foster, K. G. Anderson, Proc. R. Soc. B, 2020, 287, 2775, doi: $10.1098 / \mathrm{rspb} .2020 .2775$.

[8] M. Doi, T. Nemoto, H. Nakanishi, Y. Kuwahara, Y. Oguma, J. Chem. Ecol., 1997, 23, 2067-2078, doi: 10.1023/B:JOEC.0000006490.76693.77.

[9] F. A. Ferrara, E. F. Vilela, G. N. Jham, A. E. Eiras, M. C. Picanco, A. B. Attygalle, A. Svatos, R. T. Frighetto, J. Meinwald, 
J. Chem. Ecol., 2001, 27, 907-917, 10.1023/a:1010378818318

[10] J. P. Doskocil, N. R. Walker, G. E. Bell, S. M. Marek, J. A. Reinert, T. A. Royer, J. Econ. Entomol., 2008, 101, 1624-1632, doi: 10.1603/0022-0493(2008)101[1624:scasoo]2.0.co;2.

[11] T.J. Poprawski, W. N. Yule, J. Appl. Entomol., 1992, 114, 305-314, doi: 10.1111/j.1439-0418.1992.tb01131.x.

[12] P. S. Robbins, D. B. Cash Jr., C. E. Linn, W. L. Roelofs, J. Chem. Ecol., 2008, 34, 205-214, doi: 10.1007/s10886-008-94271.

[13] P. S. Robbins, et al. J. Chem. Ecol., 2009, 35, 336-341, doi: 10.1007/s10886-009-9593-9.

[14] P. S. Robbins, S. Nojima, S. Polavarapu, A. M. Koppenhöfer, C. Rodriguez-Saona, R. J. Holdcraft, N. H. Consolie, D. C. Peck, W. L. Roelofs, J. Insect Sci., 2006, 6, 39-163, doi: 10.1673/031.006.3901

[15] S. Nojima, P. S. Robbins, G.A. Salsbury, B. D. Morris, W. L. Roelofs, M. G. Villani, J. Chem. Ecol., 2003, 29, 2439-2446, doi: 10.1023/A:1026349716070.

[16] M. Zaragoza-Ortega, O. L. Segura-León, J. Hernández-Cruz, J. Valdez-Carrasco, S. Sánchez-Soto, Florida Entomol., 2017, 100, 546-550, doi: 10.1653/024.100.0309.

[17] E. Herjog, T. Frigato, V. Helms, C. R. D. Lancaster, J. Comp Chem., 2006, 27, 1534, doi: 10.1002/jcc.20442.

[18] I. M. Smallwood, Handbook of Organic Solvent Properties, Arnold, London 1996.

[19] G. C. Bond, Heterogeneous Catalysis: Principles and Applications, Oxford University Press, 1987.

[20] J.-B. Tan, P. Sahoo, J.-W. Wang, Y.-W. Hu, Z.-M. Zhang, T.B. Lu, Inorg. Chem. Front., 2018, 5, 310-318, doi: 10.1039/C7QI00681K.

[21] P. Sahoo, J.-B. Tan, Z.-M. Zhang, S. K. Singh, Prof. T.-B. Lu, Chem. Cat. Chem., 2018, 10, 1075-1083, doi: 10.1002/cctc. 201701790 .

[22] For coating heterogeneous catalyst on carbon nanotube: P. Sahoo, R. G. Shrestha, L. K. Shrestha, J. P. Hill, T. Takei, K. Ariga, J. Inorg. Organomet. Polym. Mater, 2016, 26, 1301-1308, doi: 10.1007/s10904-016-0365-z.

[23] P. P. Bag and P. Sahoo in "Green Photocatalyst for energy and environmental Process", Springer Nature International, 2020, Vol. 36, pp 141-186. ISBN: 978303017637 2. DOI: 10.1007/978-3-030-17638-9 6.

[24] P. Sahoo, Eng. Sci., 2021, 14, 109-113, doi: $10.30919 /$ es8d428.

[25] S. Ishihara, K. Deguchi, H. Sato, M. Takegawa, E. Nii, S. Ohki, K. Hashi, M. Tansho, T. Shimizu, K. Ariga, J. Labuta, P. Sahoo, Y. Yamauchi, J. P Hill, N. Iyi, R. Sasai, RSC Adv., 2013, 3, 19857-19860, doi: 10.1039/C3RA44231D.

[26] M. J. Frisch, G. W. Trucks, H. B. Schlegel, G. E. Scuseria, M. A. Robb, J. R. Cheeseman, G. Scalmani, V. Barone, B. Mennucci, G. A. Petersson, H. Nakatsuji, M. Caricato, X. Li, H. P. Hratchian, A. F. Izmaylov, J. Bloino, G. Zheng, J. L. Sonnenberg, M. Hada, M. Ehara, K. Toyota, R. Fukuda, J. Hasegawa, M. Ishida, T. Nakajima, Y. Honda, O. Kitao, H. Nakai, T. Vreven, J. A. Montgomery, Jr., J. E. Peralta, F. Ogliaro, M. Bearpark, J. J. Heyd, E. Brothers, K. N. Kudin, V. N. Staroverov, R. Kobayashi, J. Normand, K. Raghavachari, A. Rendell, J. C. Burant, S. S. Iyengar, J. Tomasi, M. Cossi, N. Rega, J. M. Millam, M. Klene, J. E. Knox, J. B. Cross, V. Bakken, C. Adamo, J. Jaramillo, R. Gomperts, R. E. Stratmann, O. Yazyev, A. J. Austin, R. Cammi, C. Pomelli, J. W. Ochterski, R. L. Martin, K.
Morokuma, V. G. Zakrzewski, G. A. Voth, P. Salvador, J. J. Dannenberg, S. Dapprich, A. D. Daniels, Ö. Farkas, J. B. Foresman, J. V. Ortiz, J. Cioslowski, and D. J. Fox, Gaussian 09, Revision D.01, Gaussian, Inc., Wallingford CT, 2009.

[27] T. A. Halgren, J. Comp. Chem., 1996, 17, 490 - 519, doi: $10.1002 /(\mathrm{SICI}) 1096-987 \mathrm{X}(199604) 17: 5 / 6<490:$ :AID $\mathrm{JCC} 1>3.0 . \mathrm{CO} ; 2-\mathrm{P}$.

[28] A. I. Alrawashdeh, J. B. Lagowski, RSC Adv., 2018, 8, 30520-30529, doi: 10.1039/C8RA02460J.

[29] P. Rodríguez-Cuamatzi, O. I. Arillo-Flores, M. I. BernalUruchurtu, H. Höpfl, Supramol. Chem., 2007, 19, 559-578, doi: 10.1080/10610270701474439

[30] D. Braga, L. Maini, F. Grapioni, A. de Cian, O. Felix, J. Fischer, M.W. Hosseini, New J. Chem., 2000, 24, 547-553, doi: 10.1039/B002061N.

[31] A. V. Marenich, C. J. Cramer, D. G. Truhlar, J. Phys. Chem. $B, 2009,113,6378-6396$, doi: 10.1021/jp810292n.

[32] W.-Y. Yang, J. Zheng, X.-G. Zhang, L.-C. Chen, Y. Si, F.-Z. Huang, W. Hong, J. Mater. Chem. C, 2020, 8, 481-486, doi: 10.1039/C9TC05686F.

[33] S. Mohamed, D. A. Tocher, M. Vickers, P. G. Karamertzanis, S. L. Price, Cryst. Growth Des., 2009, 9, 2881-2889, doi: $10.1021 / \operatorname{cg} 9001994$.

[34] J. S. Stevens, S. J. Byard, C. C. Seaton, G. Sadiq, R. J. Daveya, S. L. M. Schroeder, Phys. Chem. Chem. Phys., 2014, 16, 1150, doi: 10.1039/C3CP53907E.

[35] P. Sahoo, P. Dastidar, Cryst. Growth Des., 2012, 12, $5917-$ 5924, doi:10.1021/cg301245c.

[36] P. Sahoo, I. Chakraborty, P. Dastidar, Soft Matt., 2012, 8, 2595-2598, doi:10.1039/C2SM06957A

[37] P. Sahoo, R. Sankolli, H.-Y. Lee, S. R. Raghavan, P. Dastidar, Chem Euro J., 2012, 18, 8057-8063, doi: 10.1002/chem.201200986.

[38] P. Sahoo, D. K. Kumar, D. R. Trivedi, P. Dastidar, Tetrahedron Lett., 2008, 49, 3052-3055, doi: 10.1016/j.tetlet.2008.03.060.

[39] P. Sahoo, V. G. Puranik, A. K. Patra, P. U. Sastry, P. Dastidar. Soft Matt., 2011, 7, 3634-3641, doi: 10.1039/COSM01148G.

[40] P. P. Bag, Eng. Sci., 2021, 13, 98-105, doi: 10.30919/es8d1004.

[41] P. P. Bag, R. R. Kothur, C. M. Reddy, Cryst. Eng. Comm., 2014, 16, 4706-4714, doi: 10.1039/C3CE42159G.

[42] P. P. Bag, M. Patni, C. M. Reddy, Cryst. Eng. Comm., 2011, 13, 5650-5652, doi: 10.1039/C1CE05778B.

[43] P. Sahoo, N. N. Adarsh, G. E. Chack, S. R. Raghavan, V. G. Puranik, P. Dastidar, Langmuir, 2009, 25, 8742-8750, doi: 10.1021/la9001362.

[44] U. K. Das, D. R Trivedi, N. N. Adarsh, P. Dastidar, J. Org. Chem., 2009, 74, 7111-7121, doi: 10.1021/jo901463k.

\section{Author information}

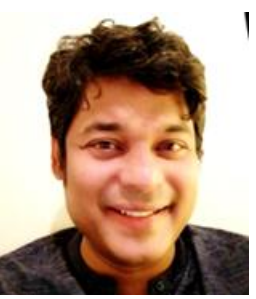

Ir. Pathik Sahoo did Master from Banaras Hindu University and pursued his PhD from Indian Association for the Cultivation of Science, India on 'Designing Low Molecular Weight Gelator: A crystal Engineering Approach' in 2012. He works 
at National Institute for Materials Science, Japan as a postdoctoral fellow. His current research focus is mainly on Gel Computation, 3D holographic lens, developing Brain Jelly based artificial brain, etc. He is the visiting Professor of Foundation of Physics Research Center (FoPRC), Italy. Besides pursuing research, the author also plays an Indian percussion, tabla since his childhood.

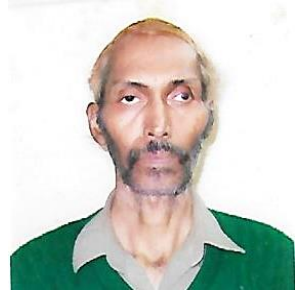

Prof. Pradip Das has Bachelor of Science with First Class Honours in Chemistry and First Class Master of Science with specialisation in Physical Chemistry, both from University of Calcutta, India. He did his Ph.D in Physical Chemistry under the supervision of Professor Carl W. Garland at the Massachusetts Institute of Technology, Cambridge, Massachusetts, followed by 3-year postdoctoral work at the Johns Hopkins University, Baltimore, Maryland. After spending several years in Lecturer and Reader positions, he became Professor of Chemistry at Bose Institute, Kolkata, India in 2011. His research interests are in calorimetry, X-ray and theoretical works relevant to Liquid Crystal phase transitions.

Publisher's Note: Engineered Science Publisher remains neutral with regard to jurisdictional claims in published maps and institutional affiliations. 